\title{
Toxoplasma gondii is not an important contributor to poor reproductive performance of primiparous ewes from southern Australia: a prospective cohort study
}

\section{Thomas Clune}

Murdoch University

Amy Lockwood

Murdoch University

Serina Hancock

Murdoch University

Andrew Thompson

Murdoch University

Mieghan Bruce

Murdoch University

\section{Sue Beetson}

Murdoch University

Angus Campbell

University of Melbourne

Elsa Glanville

University of Melbourne

Daniel Brookes

University of Melbourne

Colin Trengove

University of Adelaide

Ryan O'Handley

University of Adelaide

Caroline Jacobson ( $\sim$ C.Jacobson@murdoch.edu.au )

Murdoch University

\section{Research Article}

Keywords: Toxoplasmosis, lamb survival, abortion, lamb mortality, sheep, parasite, reproduction

Posted Date: October 29th, 2021 
DOl: https://doi.org/10.21203/rs.3.rs-955972/v1

License: (c) (1) This work is licensed under a Creative Commons Attribution 4.0 International License. Read Full License

Version of Record: A version of this preprint was published at BMC Veterinary Research on March 19th, 2022. See the published version at https://doi.org/10.1186/s12917-022-03211-w. 


\section{Abstract \\ Background}

Toxoplasma gondii causes reproductive losses in sheep worldwide, including Australia. The reproductive performance of primiparous ewes is typically lower than for mature multiparous ewes, and younger ewes are more likely to be immunologically naïve and therefore more susceptible to reproductive disease if $T$. gondii infection occurs during pregnancy. The aim of this study was to assess the impact of infection with $T$. gondii on the reproductive performance of primiparous ewes in southern Australia using a prospective cohort study. This will inform the need for targeted control strategies for $T$. gondii in Australian sheep.

\section{Results}

Toxoplasma gondii seropositivity using indirect ELISA was detected at 16/28 farms located across southern Australia. Apparent seroprevalence was lower in primiparous ewes (1.1\%, 95\% confidence interval $(\mathrm{Cl}) 0.6,1.8)$ compared to mature multiparous ewes $(8.1 \%, 95 \% \mathrm{Cl} 6.0,10.5 ; P<0.001)$.

Toxoplasma gondii seroconversion during the gestation and lambing period was confirmed for $11 / 1097$ $(1.0 \%, 95 \% \mathrm{Cl} 0.5,1.7)$ of pregnant primiparous ewes that failed to raise a lamb, and $1 / 161(0.6 \%, 95 \% \mathrm{Cl}$ $0.1,2.9)$ primiparous ewes with confirmed abortion. Toxoplasma gondii was not detected using qPCR in tissue samples from aborted or stillborn lambs $(n=35)$ from a subset of six farms.

\section{Conclusions}

Low seroprevalence and low incidence of seroconversion during gestation suggests that toxoplasmosis was not an important contributor to reproductive losses in primiparous ewes on farms located over a wide geographical area in southern Australia.

\section{Background}

The number of lambs weaned from primiparous ewes is typically lower and more variable compared to multiparous ewes [1-3]. However, little research has investigated the causes of foetal and lamb mortality occurring between pregnancy diagnosis in mid-pregnancy and weaning for primiparous ewes.

Toxoplasmosis is a globally important disease of sheep that is caused by infection with Toxoplasma gondii and can cause early embryonic deaths, abortions, stillbirths, premature lambs and the birth of weak lambs that have poor survival rates. Zoonotic transmission of $T$. gondii via ingestion of viable cysts in undercooked sheepmeat is also an important public health issue [4-6].

Sheep can be infected with $T$. gondii via ingestion of feed or water contaminated with oocysts that have been shed by a feline definitive host [7]. Vertical transmission after pregnancy-induced recrudescence of 
persistent infections has also been reported $[8,9]$. Reproductive disease is generally observed only following a primary infection in a naïve pregnant ewe, and $T$. gondii infection usually confers long-lasting protective immunity [10]. Hence, the likelihood of infection and thus immunity increases with age [11, 12]. Young ewes are therefore more likely to be immunologically naïve and susceptible to reproductive disease if exposed to infective oocysts during gestation.

Toxoplasmosis is identified as a sporadic cause of abortion in ewes in southern Australia [13]. However, the incidence of reproductive disease associated with toxoplasmosis in Australian ewes is not well described. Serological surveys conducted in Australian sheep have demonstrated that $T$. gondii has a broad geographical distribution with reports of seroconversion on $41-97 \%$ of the studied farms and mean individual animal prevalence ranging from 7-62\% [14-21]. However, most of these studies were restricted to specific regions or do not discriminate between age groups of sheep.

Whilst T. gondii is endemic in Australia, its impact on ewe reproduction, and specifically reproduction for primiparous ewes, is not well quantified. A seroprevalence survey in South Australia reported a negative correlation between within-flock T. gondii seroprevalence and lamb marking rate [20]. However, this study did not investigate seroprevalence between ewe age groups or determine the timing of $T$. gondii seroconversion relative to reproductive outcome. Similar to the South Australian survey, a study in Uruguay identified lower lambing rates for ewes that seroconverted for T. gondii during gestation [22]. Vaccination against $T$. gondii was associated with increased lamb marking percentages in extensively managed primiparous ewe lambs in New Zealand which suggests that toxoplasmosis was impacting reproduction in flocks that were not vaccinated [23].

The aim of this study was to assess the impact of $T$. gondii infection on the reproductive performance of primiparous ewes in southern Australia. This will inform the need for targeted control strategies for $T$. gondii in Australian sheep.

\section{Results}

\section{Primiparous ewe reproductive performance}

Foetal loss and lamb mortality for progeny of primiparous ewes was outlined by Clune et al. [24]. Foetal and lamb mortality between scan 1 (approximately 85 days from the start of mating) and lamb marking (approximately 6 weeks from the start of lambing) was 36\% (1567/4351 foetuses; range 14 - 71\%) for primiparous ewe lambs and 29\% (582/2103 foetuses; range 20 - 53\%) for primiparous yearlings. Abortion (pregnancy loss between scan 1 and scan 2) was detected in 14/19 primiparous ewe lamb flocks and $6 / 11$ primiparous yearling flocks. In primiparous ewe lamb flocks, abortion was detected in $5.2 \%$ (155/2968) ewes, ranging $0-50.0 \%$ across flocks. In primiparous yearling flocks, abortion was detected in $0.8 \%(16 / 1886)$ ewes, ranging $0-4.4 \%$ across flocks.

\section{Toxoplasma gondii seroprevalence}


Apparent and true T. gondii seroprevalence for ewe age categories are shown in Table 1. Apparent $T$. gondii seroprevalence for primiparous ewes (ewe lambs and yearlings combined) was $1.1 \%(95 \% \mathrm{Cl} 0.6$, 1.8). Apparent individual-animal $T$. gondii seroprevalence was higher for mature ewes compared to primiparous ewe lambs $(P<0.001)$ and primiparous yearling ewes $(P<0.001)$. There was no difference in the apparent seroprevalence between primiparous ewes mated as ewe lambs or yearlings $(P=0.214)$.

Toxoplasma gondii seropositivity was detected in at least one ewe for $16 / 28(57 \%)$ of the farms. Toxoplasma gondii seropositivity was identified in 12/30 (40\%) of primiparous ewe flocks and 11/28 (39\%) of mature ewe flocks. For flocks where T. gondii seropositivity was detected, within-flock seroprevalence ranged from 1-5\% for primiparous ewes (Additional File 1) and 5-50\% for mature ewes (Additional File 2). The majority (82\%) of seropositive mature ewes were detected on five farms where within-flock seroprevalence for mature ewes ranged 25-50\% (Additional File 2).

Table 1

Apparent T. gondii seroprevalence and estimated true prevalence for primiparous ewes mated as ewe lambs (approximately one-year-old at sampling) or yearlings (approximately two-years old at sampling) and mature multiparous ewes (aged 3 years or older) from 28 Australian farms.

\section{Ewes sampled}

$\begin{array}{lll}\text { Flocks } & \text { Individual } & \text { Seropositive } \\ (n) & \text { ewes }(n) & \text { samples }(n)\end{array}$
Apparent seroprevalence
Estimated true prevalence
$\%(95 \% \mathrm{Cl})$
$\%(95 \% \mathrm{Crl})$

\section{Primiparous}

ewes

$\begin{array}{lccccc}\text { Ewe lambs } & 19 & 839 & 7 & 0.8(0.4,1.6)^{\mathrm{a}} & 0.7(0.1,1.6) \\ \begin{array}{l}\text { Yearling } \\ \text { Mature }\end{array} & 11 & 440 & 7 & 1.6(0.7,3.1)^{\mathrm{a}} & 1.6(0.4,3.1) \\ \begin{array}{l}\text { ewes } \\ \text { ewe }\end{array} & 28 & 558 & 45 & 8.1(6.0,10.5)^{\mathrm{b}} & 8.1(5.8,10.6)\end{array}$

95\% Cl: $95 \%$ confidence interval

95\% Crl: $95 \%$ credible interval

ab Apparent seroprevalence values with different superscripts are significantly different (two sample proportion z-test (2-tailed) $P<0.05$ )

\section{Timing of T. gondii seroconversion in primiparous ewes}

Toxoplasma gondii seropositivity was detected for 7 ewes joined as ewe lambs and 7 ewes joined as yearlings (Table 1). Of these, confirmed outcome of pregnancy and serial blood samples were available for 12 ewes. The timing of detection of seroconversion in these 12 ewes is shown in Table 2. Overall, $T$. gondii seroconversion after the pre-mating blood sampling was detected for $11 / 1097(1.0 \%, 95 \% \mathrm{Cl} 0.5$, 1.7) of the primiparous ewes selected for serology that failed to raise a lamb. For the subset of ewes 
selected for serology that had confirmed abortion, T. gondii seroconversion after mating was detected for $1 / 161(0.6 \%, 95 \% \mathrm{Cl} 0.1,2.9)$ ewes (Table 2$)$. Seropositivity was also detected in a second ewe that aborted but did not have serial blood samples available to determine timing of seroconversion.

Serum samples categorised as negative for $T$. gondii $\lg G$ at a sampling timepoint after detection of $T$. gondii seroconversion were detected for only one ewe (Ewe 3479; Table 2). 
Table 2

Timing of detection for T. gondii IgG seroconversion using indirect ELISA for primiparous ewes $(n=12)$ sampled across southern Australia between 2018 and 2020. The earliest detection of seroconversion is bolded.

\begin{tabular}{|c|c|c|c|c|c|c|c|}
\hline \multirow{2}{*}{$\begin{array}{l}\text { Ewe } \\
\text { ID }\end{array}$} & \multirow[t]{2}{*}{ Farm } & \multirow{2}{*}{$\begin{array}{l}\text { Timing of foetal or } \\
\text { lamb loss }\end{array}$} & \multicolumn{5}{|c|}{ T. gondii seroconversion status } \\
\hline & & & $\begin{array}{l}\text { Pre- } \\
\text { joining }\end{array}$ & Scan 1 & Scan 2 & $\begin{array}{l}\text { Pre- } \\
\text { lambing }\end{array}$ & $\begin{array}{l}\text { Lamb } \\
\text { marking }\end{array}$ \\
\hline \multicolumn{8}{|c|}{ Seroconversion detected pre-joining } \\
\hline 9463 & 13 & Perinatal death & Positive & Positive & Positive & NA & Positive \\
\hline \multicolumn{8}{|c|}{ Seroconversion first detected during pregnancy } \\
\hline 18842 & 20 & $\begin{array}{l}\text { Late abortion/ } \\
\text { perinatal lamb death }\end{array}$ & Negative & Positive & Positive & NA & Positive \\
\hline 18857 & 20 & Perinatal death & Negative & Positive & Positive & NA & Positive \\
\hline 3479 & 3 & $\begin{array}{l}\text { Late abortion/ } \\
\text { perinatal lamb death }\end{array}$ & Negative & Positive & Negative & Negative & Positive \\
\hline 12114 & 12 & $\begin{array}{l}\text { Mid Abortion } \\
\text { (scan } 2-\operatorname{scan} 3)\end{array}$ & Negative & Negative & Positive & NA & NA \\
\hline 13091 & 7 & $\begin{array}{l}\text { Late abortion * } \\
\text { (scan } 3-\text { pre- } \\
\text { lambing) }\end{array}$ & Negative & Negative & Negative & Positive & NA \\
\hline 18121 & 21 & Perinatal death & Negative & Negative & Negative & Positive & Positive \\
\hline
\end{tabular}

\section{Seroconversion first detected at marking}

$\begin{array}{llllllll}16527 & 10 & \text { Perinatal death } & \text { Negative } & \text { Negative } & \text { Negative } & \text { NA } & \text { Positive } \\ 16528 & 10 & \text { Perinatal death } & \text { Negative } & \text { Negative } & \text { Negative } & \text { NA } & \text { Positive } \\ 17152 & 15 & \text { Perinatal death } & \text { Negative } & \text { Negative } & \text { Negative } & \text { Negative } & \text { Positive } \\ 18190 & 22 & \text { Perinatal death } & \text { Negative } & \text { Negative } & \text { Negative } & \text { Negative } & \text { Positive } \\ 23364 & 29 & \text { Raised twins } & \text { Negative } & \text { NA } & \text { NA } & \text { Negative } & \text { Positive }\end{array}$

NA - not available for testing as the ewe was not present for sampling or had been removed from the study flock after abortion was confirmed

*confirmed late abortion based on observation of purulent vaginal discharge and opportunistic transabdominal ultrasound at the pre-lambing visit

\section{Molecular detection of T. gondii in tissues from aborted and stillborn lambs}


Toxoplasma gondii was not detected in any tissue samples from 35 aborted or stillborn lambs recovered from primiparous ewes from seven flocks on the subset of six farms in Western Australia [3].

One aborted lamb recovered from a primiparous ewe lamb flock in Victoria (Flock 19) between scan 2 and pre-lambing had evidence of multifocal encephalitis suggestive of protozoal disease. However, no protozoal organisms were observed upon histological examination, and there was no evidence of $T$. gondii seropositivity for primiparous ewes in this flock (Additional file 1). There was also no evidence of T. gondii seropositivity for primiparous ewes from the same property sampled in the following year (Flock 27; Additional file 1), nor mature ewes on the same property (Additional file 2). Campylobacter fetus was cultured from the same aborted foetus and other aborted foetuses from the same flock, indicating that campylobacteriosis was the most likely cause of abortion in this flock.

\section{Discussion}

Toxoplasmosis was not an important contributor to foetal and lamb mortality between pregnancy scanning and marking for the primiparous ewe flocks in this study. Whilst $T$. gondii seropositivity was detected by indirect ELISA on $57 \%$ of farms suggesting widespread exposure at farm level, seroconversion after mating was evident for only $1 \%$ of primiparous ewes that were confirmed to be pregnant and subsequently failed to raise a lamb. Low incidence of $T$. gondii seroconversion in primiparous ewes was consistent with the absence of detection of T. gondii using qPCR on aborted and stillborn lambs from a subset of farms. These findings are in accord with a recent review of submissions to Australian veterinary laboratories that reported T. gondii was implicated in $5 \%$ of sheep abortion investigations, and suggests that toxoplasmosis is a sporadic cause of abortion in Australian sheep [13]. In contrast, T. gondii is considered a significant economic and production-limiting pathogen in New Zealand and the United Kingdom where vaccination is utilised to reduce associated losses [10, 25]. Our findings indicate that routine vaccination for toxoplasmosis is unlikely to be economically justified for many Australian sheep producers unless there is evidence indicting high risk of exposure to T. gondii and toxoplasmosis contributing to reproductive disease for sheep in the specific region.

This study used serial serology to assess the timing of seroconversion relative to the timing of abortion or lamb death for primiparous ewes that were seropositive at lamb marking. Reproductive disease associated with toxoplasmosis is most likely to occur when primary infection of a naïve ewe occurs during pregnancy, with the outcome of infection being largely dependent on the timing of exposure $[7,26]$. Detection of IgG antibodies is reported to occur from 2-3 weeks post-infection [27], and abortions may occur within 1-2 weeks of infection [26, 28-30], or approximately 3-8 weeks post-infection, depending on stage of gestation when infection occurred [26, 29, 31, 32]. Toxoplasma gondii IgG antibodies are detectable by P30 ELISA between 3 and 10 weeks after infection [33] and persist for several years [34]. So, it is unlikely that antibodies would have failed to rise to detectable levels or waned to below detectable levels by lamb marking if ewes had become infected with T. gondii during pregnancy and foetal or lamb mortality was related to toxoplasmosis. Based on these assumptions, toxoplasmosis was a plausible aetiology for abortions in only two ewes (12114 and 13091; Table 2). The relationship for 
timing of seroconversion relative to abortion or lamb death was less clear for other ewes (Table 2), consistent with the notion that a spectrum of outcomes may occur for pregnant ewes that become infected with T. gondii (and particularly during late gestation).

An unclear association between timing of $T$. gondii seroconversion and abortion in some ewes was also consistent with observation that other factors were likely to be contributing to abortion or perinatal lamb deaths in these flocks. Abortions, stillbirths and polyarthritis associated with Chlamydia pecorum were detected in primiparous ewe flocks from Western Australia, and non-infectious causes of death (including dystocia and starvation-mismothering) were important contributors to cause of lamb death identified at necropsy $[3,35]$. There was no evidence neosporosis was contributing to foetal or lamb mortality in these flocks [24].

The selection of primiparous ewe for serological surveillance was biased towards ewes that aborted or failed to rear lambs. Therefore, it was not possible to determine the risk for foetal and lamb mortality associated with seroconversion during gestation. Notwithstanding this, even if seroconversion during pregnancy was associated with a higher relative risk of failing to rear a lamb, the low incidence of seroconversions during pregnancy in primiparous ewes that failed to raise lambs suggests that toxoplasmosis was unlikely to be an important contributor to reproductive losses between scanning and marking on these farms.

Attempting to relate maternal antibody titre to the occurrence of abortion or lamb mortality can be unreliable [32]. Seropositivity may be detected in ewes who successfully rear lambs either due to the enduring nature of IgG antibodies from infections prior to gestation or the spectrum of outcomes that may occur when naïve ewes become infected during gestation. While extensive laboratory testing was not performed across all sites, the low incidence of $T$. gondii seroconversion for primiparous ewes that aborted or failed to raise lambs was supported by the absence of detection of $T$. gondii via molecular methods on a subset of farms in Western Australia [3]. Association between T. gondii seroconversion in ewes and foetal or lamb mortality in this study could be confirmed using foetal serology [32], molecular diagnostics [36], and histopathology [37] for tissues from a larger subset of lambs that were aborted or died during perinatal period. Additionally, quantitative serology to evaluate changes in titre for ewes with suspected toxoplasmosis would have allowed a more accurate interpretation of serial serological results. Nevertheless, even if foetal and lamb mortality for all ewes that were seropositive at lamb marking was due to toxoplasmosis, this still represents a very small contributor to overall foetal and lamb mortality in these flocks.

This study reported seroprevalence for ewes that were determined to be pregnant by transabdominal ultrasound and subsequently aborted or failed to raise lambs. However, toxoplasmosis can also have impacts on early pregnancy before pregnancy scanning, including embryonic death, resorption and early foetal mortality [38]. This study did not determine association between T. gondii seroconversion and pregnancy status at Scan 1. It is possible that infections occurring early in pregnancy could result in primiparous ewes being not pregnant at scanning. Low seroprevalence reported in this study for 
primiparous ewes that were pregnant at scan 1 suggests that toxoplasmosis was unlikely to be an important contributor to early reproductive losses on these farms. However, further investigation is required to determine if infection early in pregnancy is an important contributor to early pregnancy loss evident as ewes that are not pregnant at scanning.

Toxoplasma gondii seropositivity was detected for $57 \%$ of farms in this study, providing further evidence for the parasite's endemicity and suggesting that exposure to T. gondii occurs on many Australian sheep farms. This was consistent with other Australian studies reporting farm-level seroprevalence ranging $41-$ $97 \%[15,16,18,20]$. Seroprevalence in mature ewes $(8.1 \%)$ was within the $7 \%-57 \%$ range reported for other Australian studies in the last 15 years [17-21], and similar to national seroprevalence $11.5 \%$ (46/401) reported for mutton (mature sheep) in a recent Australian abattoir survey [21].

Individual-animal T. gondii seroprevalence for primiparous ewes in our study (1.1\%) was lower than two previous studies reporting seroprevalence of $15 \%$ and $17 \%$ for Australian slaughter-age lambs in abattoir surveys $[14,17]$. The most recent abattoir survey reporting seroprevalence in lambs used a commercial modified latex agglutination test (Eiken Indirect Latex Agglutination Test) [17]. Our study used a commercial indirect ELISA that has good sensitivity and specificity relative to latex agglutination test for sheep sera reported by the manufacturer [39], suggesting that differences in testing methodology are unlikely to explain the difference in seroprevalence between the studies. It is therefore more likely that the low seroprevalence in primiparous ewes reflects the sporadic nature of $T$. gondii infection in Australian sheep rather than differences in serological methods.

Flock and animal seroprevalence in mature ewes indicated variable exposure to T. gondii on Australian sheep farms. Most seropositive mature ewes were concentrated on five farms where within-farm seroprevalence ranged $25-50 \%$. Variable seroprevalence in Australian sheep contrasts to the more consistent exposure reported for sheep farms in New Zealand, United States and United Kingdom [11, 12, 40], and suggests sporadic point source exposure to oocysts, likely via contaminated drinking water or feed source, are the major source of $T$. gondii exposure on Australian sheep farms. The higher (50\%) seroprevalence observed for ewes on a farm on Kangaroo Island (Additional file 2) was consistent with previous studies reporting high $T$. gondii seroprevalence on Kangaroo Island [19, 20]. Interestingly, there was no evidence of seropositivity in the primiparous ewes from the farm on Kangaroo Island, consistent with sporadic exposure to $T$. gondii. The risk of $T$. gondii exposure is associated with a range of factors including abundance of cats, access to surface water and rainfall [41, 42]. The number of farms included in this study was too small to compare seroprevalence across regions, and further work is warranted to determine regional differences in T. gondii exposure and incidence of toxoplasmosis. Improved understanding of regional variation and risk factors for $T$. gondii exposure on Australian sheep farms would inform cost-benefit analyses for interventions to reduce the risk of toxoplasmosis.

Sampling primiparous ewes was biased towards ewes that were determined to be pregnant and subsequently failed to rear a lamb. If toxoplasmosis was an important contributor to foetal and lamb mortality on these farms, then this sampling bias could result in overestimation of seroprevalence relative 
to the general population. However, there was no difference observed in flock-level seroprevalence for primiparous ewes compared to multiparous ewes.

The commercial ELISA used in our study has been utilised for other seroprevalence surveys in sheep [18, 43-45], but there is a lack of published data validating the test against other 'gold standard' tests such as microagglutination tests or PCR. A commercial modified agglutination test for T. gondii was validated for Australian sheep [21], but this test is no longer available. The indirect ELISA used in this study was found to have good agreement with modified agglutination test on a subset of sheep sera collected from another study (Additional file 3). Further validation of commercial indirect ELISA for natural T. gondii infections in Australian sheep will inform improved estimation of true prevalence for field studies.

Whilst the observations from this study do not support the need for widespread routine vaccination to reduce foetal and lamb mortality for primiparous ewes in Australia, T. gondii is endemic on Australian farms and associated with sporadic reproductive losses on some farms [13]. The low rates of seropositivity in primiparous and multiparous ewes suggests a lack of protective immunity in a large proportion of ewes [10]. These ewes remain susceptible to reproductive disease if a toxoplasmosis outbreak was to occur during gestation, most likely through point source exposure to oocysts via contamination of drinking water or feed source. Control of feral and domestic cat populations on sheep farms and measures to prevent contamination of feed and water sources from cat faeces can reduce the risk of toxoplasmosis outbreaks in susceptible sheep. Vaccination could be warranted in some regions where high farm and individual animal seroprevalence is identified [20], and high incidence of reproductive losses due to $T$. gondii are confirmed using foetal and lamb necropsy and laboratory investigation. The interpretation of $T$. gondii serology for the purpose of diagnosing toxoplasmosis is challenging, particularly for field investigations of reproductive loss in extensive sheep production systems where abortions or unusually high incidence of perinatal mortality are challenging to detect at the time losses are occurring. Diagnosis of toxoplasmosis should be supported with detection of $T$. gondii in tissues where possible, as well as the exclusion of other endemic pathogens.

\section{Conclusion}

Toxoplasmosis was not a significant contributor to abortion and perinatal lamb mortality for primiparous ewes on farms across southern Australia. Seropositivity to $T$. gondii for mature multiparous ewes was detected by indirect ELISA on more than half of the farms included in this study. However, only $1 \%$ of primiparous ewes that had confirmed pregnancy and subsequently failed to raise a lamb had evidence of $T$. gondii seroconversion after mating. Low incidence of $T$. gondii seroconversion in primiparous ewes during gestation was consistent with the absence of detection of $T$. gondii using qPCR on aborted and stillborn lambs from a subset of farms.

\section{Methods And Study Design}

\section{Study design, animals and research sites}


This cohort study was conducted between 2018 and 2020, using 30 primiparous ewe flocks on 28 farms located in Western Australia $(n=11)$, South Australia $(n=9)$, and Victoria $(n=10)$ (Figure 1) previously described [24]. Farms were located over a wide geographic area that incorporated different rainfall zones (Figure 1 and Additional file 1). Farms were selected for inclusion based on convenience sampling; having at least 200 primiparous ewes available for the study, capacity to monitor ewes and their progeny over the study period, and with sheep genotype and management that were generally representative of standard commercial sheep farms in the region. Some farms included in the study managed flocks of stud sheep which may increase frequency of monitoring relative to commercial flocks, but the housing (i.e. all flocks were managed in paddocks for the duration of the study) and stocking intensity were broadly comparable to commercial sheep flocks in these regions.

Each flock was monitored during gestation and lambing. Merino and non-Merino breeds were included in the study (Additional file 1). Non-Merino flocks included Border Leicester, Dorper, White Suffolk and composite breeds. Ewes were mated as either ewe lambs (7-10 months, $n=19$ flocks) or primiparous yearlings (18-20 months, $n=11$ flocks). At each farm, twenty mature multiparous ewes aged three years or older that had been bred on the same farm were randomly selected for blood sampling only (Additional file 2). All farms ran self-replacing flocks and ewes included in the study were managed according to standard farm practice.

\section{Animal measurements and sample collection}

Foetal mortality for primiparous ewes was determined based on sequential transabdominal pregnancy ultrasounds (scans). Scan 1 was conducted approximately 85 days (range 62-101) from the start of mating. Scan 2 was conducted at least 30 days after the first scan at approximately 118 days (range 107136) from the start of mating. The outcome of pregnancy and perinatal lamb mortality were determined based on number (single, twin or triplet) and survival status (lambs dead or alive) for lambs at lambing rounds and at lamb marking (approximately six weeks from the start of lambing). Ewe lactation status (lactating or not lactating) was determined by visual observation and/or palpation of the udder at lamb marking.

Blood samples for primiparous ewes were collected at five timepoints: pre-mating, scan 1, scan 2, prelambing (approximately 140 days from start of mating) and lamb marking (approximately 6 weeks from start of lambing). Blood samples for mature ewes were obtained at a single timepoint during the study period, but timing of sampling relative to lambing and their reproductive outcome was not recorded (Additional File 2).

All blood samples were obtained by jugular venepuncture into serum vacutainer tubes with clot activator and stored on ice or at $2^{\circ} \mathrm{C}$. Within 72 hours of collection, blood samples were centrifuged at $4000 \mathrm{rpm}$ for 10 minutes and serum was decanted into $2 \mathrm{~mL}$ low protein-binding polypropylene screw cap micro tubes and stored at $-20^{\circ} \mathrm{C}$ prior to serological testing.

\section{Serology sample selection}


All samples from mature ewes and a sub-sample of at least 40 primiparous ewes from each flock were selected for $T$. gondii serology. Samples for primiparous ewes that were identified as pregnant at the first pregnancy scan but failed to successfully rear a lamb were prioritised for screening. That is, sample selection for primiparous ewes was biased towards ewes that were pregnant and failed to rear a lamb. This included primiparous ewes that were determined to have aborted and ewes for which lamb mortality occurred in the perinatal period. Samples for primiparous ewes that reared lambs were also included for screening where flocks had less than 40 ewes that failed to rear a lamb (Additional file 1). Blood samples collected at lamb marking were used for serology where available. For primiparous ewes where blood samples from marking were not available, blood samples collected at the latest available timepoint were used (i.e. blood sample collected at scan 2 or pre-lambing after foetal mortality was detected). For primiparous ewes that returned a 'positive' result using indirect ELISA at the last time-point, serum samples from earlier timepoints (pre-joining, scan 1, scan 2 and pre-lambing) were tested to determine the timing of seroconversion relative to gestation and foetal or lamb mortality.

\section{Toxoplasma gondii serology}

Anti-T. gondii IgG seropositivity was determined using commercial indirect ELISA (ID Screen Toxoplasmosis Indirect Multispecies, ID Vet, France) according to the manufacturer's instructions [39]. Testing was performed by VETPATH Laboratories (Perth, Western Australia). The results were read at 450 nm using a Multiskan FC, Thermo Scientific spectrophotometer. Positive and negative internal controls were included with each plate. Optical density (OD) values were expressed as the mean percentage of sample/positive $(\mathrm{S} / \mathrm{P})$ values, as recommended by the manufacturer: $\mathrm{S} / \mathrm{P}$ value $=\left(\mathrm{OD}_{\text {sample }}{ }^{-}\right.$ $\left.O D_{\text {negative.control }}\right) /\left(O D_{\text {positive control }}-\mathrm{OD}_{\text {negative.control }}\right)$. Serum samples were classified as positive (S/P value $\geq 50$ ), doubtful (S/P value 40 to $<50$ ) or seronegative ( $/ \mathrm{P}$ value $<40$ ) according to the manufacturer's recommendation. This assay has a specificity of $100 \%(95 \% \mathrm{Cl} 98.2,100)$ and a sensitivity of $100 \%(95 \% \mathrm{Cl} 89.1,100)$ using sheep sera validated against latex agglutination test (MAST Group) according to the manufacturer's internal validation report [39]. A subset of sera from Australian sheep previously tested with a validated modified agglutination test [21] in a separate study were retested using the commercial indirect ELISA, with sensitivity $90.5 \%(95 \% \mathrm{Cl} 71.1,98.3)$ and specificity 100\% (95\% Cl 64.6, 100) (Additional file 3).

Samples that returned a 'doubtful' result (Additional file 4) and a subset of samples that returned a negative result (Additional file 5) were re-tested using an alternate commercial ELISA test (IDEXX Toxotest, IDEXX Laboratories, Switzerland), according to manufacturer's instructions. Re-testing was performed by Department of Primary Industry and Regional Development Diagnostic Laboratory Service. Each plate included positive and negative controls. The results were read at $450 \mathrm{~nm}$ using a Multiskan EX, Thermo Fisher Scientific spectrophotometer. Optical density (OD) values were expressed as the mean percentage of sample/positive $(\mathrm{S} / \mathrm{P})$ values, as recommended by the manufacturer: $\mathrm{S} / \mathrm{P}$ value $=$ $\left(O D_{\text {sample }}-O D_{\text {negative.control }}\right) /\left(O D_{\text {positive control }}-O D_{\text {negative.control }}\right)$. Serum samples were classified as positive ( $S / P$ value $\geq 100$ ), weak positive ( $/ P$ value 30 to $<100)$, suspect ( $/ P$ value $20 \leq 30$ ) or negative 
$(\mathrm{S} / \mathrm{P}$ value $<20)$ according to the manufacturer's recommendation. This assay has reported specificity $97.5 \%(95 \% \mathrm{Cl} 92.5,99.4)$ and a sensitivity $90.9 \%(95 \% \mathrm{Cl} 83.4,95.6)$ for sheep [47].

Samples that were 'doubtful' for the first test (using ID Screen $®$ ) but 'positive' or 'weak positive' for the second test (using IDEXX Toxotest) were categorised 'positive'. Results that were 'doubtful' for first test and 'negative' or 'suspect' for second test were considered negative (Additional file 4).

\section{Toxoplasma gondii detection in tissues from aborted and stillborn lambs}

Tissue samples from aborted $(n=2)$ or stillborn $(n=33)$ lambs recovered from a subset of seven flocks of primiparous ewes (Flocks 1, 2, 3, 7, 11, 14, 16) from six farms in Western Australia were submitted to the Department of Primary Industry and Regional Development Diagnostic Laboratory Services (Perth, Western Australia). Tissue samples were screened for T. gondii using qPCR as previously described [3]. Three aborted foetuses were opportunistically recovered from Flock 19 in Victoria and submitted to the Veterinary Diagnostic Services Laboratory, Victoria (Department of Jobs, Precincts and Regions).

\section{Statistical methods}

Lamb mortality was calculated based on the number of lambs alive at marking expressed as a proportion of the number of foetuses identified at scan 1. Lamb mortality was classified as 'abortion' based on detection of pregnancy loss between scan 1 and scan 2 (and validated with lambing records and ewe lactation status). Abortion was expressed as a proportion (\%) of ewes with abortion detected between scan 1 and scan 2 relative to the number of ewes that were confirmed pregnant at scan 1 .

Apparent T. gondii seroprevalence was calculated using the number of ewes categorised as positive expressed a proportion (\%) of the ewes tested, with $95 \%$ confidence intervals determined using Jeffreys method [48]. Apparent T. gondii seroprevalence were compared for the ewe age categories using a twotailed two-sample proportion z-test [49].

The true prevalence and $95 \%$ credible intervals $(95 \% \mathrm{Crl})$ were estimated using Bayesian inference, considering the sensitivity and specificity and their $95 \%$ Crl derived from manufacturer's internal validation report [39] as beta-pert distribution for priors [50].

\section{Abbreviations}

$\mathrm{Cl}$

Confidence interval

$\mathrm{Crl}$

Credible interval

ELISA

Enzyme-linked immunosorbent assay

qPCR 


\section{Declarations}

\section{Ethics approval and consent to participate}

All procedures were conducted according to guidelines of the Australian Code of Practice for the Use of Animals for Scientific Purposes and were approved by the Murdoch University Animal Ethics Committee (R3004/17). The owners of sheep included in this study provided consent to participate.

\section{Consent for publication}

The owners of sheep included in this study have consented to publication of this manuscript. The manuscript was approved for publication by Meat and Livestock Australia (funding body).

\section{Availability of data}

The datasets generated and/or analysed during the current study are not publicly available but are available from the corresponding author on reasonable request pending permission from the funding body (Meat and Livestock Australia).

\section{Competing interests}

Angus Campbell is a current Associate Editor for BMC Veterinary Research Journal. None of the authors of this paper have a financial or personal relationship with other people or organisations that could inappropriately influence or bias the content of the paper.

\section{Funding}

This project was funded by Meat and Livestock Australia (B.AHE.0318). Meat and Livestock Australia approved the study design and approved the manuscript for publication but was not involved in the collection, analysis or interpretation of data, or in the writing of the manuscript. Molecular diagnostic 
testing for aborted and stillborn lambs was performed under the Western Australian Ewe Abortion and Newborn Lamb Death Surveillance Program (Department of Primary Industries and Regional Development, Western Australia). Thomas Clune received post-graduate scholarships from Meat and Livestock Australia and Sheep Industry Business Innovation (Department of Primary Industries and Regional Development, Western Australia). Equipment used for this project was funded by the Murdoch University Veterinary Trust.

\section{Author contributions}

Conceptualisation: $\mathrm{TC}, \mathrm{CJ}, \mathrm{SH}, \mathrm{AT}, \mathrm{SB}$

Methodology: TC, CJ, SB, RO

Formal analysis and investigation: $T C, C J, M B, A L, S H, A C, E G, D B, C T, R O$

Writing - original draft preparation: $\mathrm{TC}, \mathrm{CJ}, \mathrm{AL}$

Writing - review and editing: TC, AL, SH, AT, M, SB, AC, EG, DB, CT, RO, CJ

Funding acquisition: $\mathrm{CJ}, \mathrm{SH}, \mathrm{AT}$

Resources: CJ, SH, AT, RO

Supervision: CJ, SH, AT

\section{Acknowledgements}

We thank the participating farmers who provided access to their animals and facilities, conducted lambing rounds, and collected and stored lambs for necropsy. We thank Celia Smuts, Janine Simmonds and the staff at VetPath Laboratories for their feedback on testing methodology and assistance with the serological testing. We thank Cameron Loomes and the staff at Department of Primary Industry and Regional Development Diagnostic Laboratory Service for their feedback on methodology and assistance with serological testing. We thank Tom La and Nyree Philip (Murdoch University), Louis Lignereux and Rob Paterson (University of Adelaide), Andrew Whale, Mary McQuillan and Patrick Hannemann (Livestock Logic, Hamilton, Victoria), Sean McGrath (Millicent Veterinary Hospital), Simon Edwards and Michelle Smart (Willunga Veterinary Hospital), and Lauryn Stewart and Deb Lehmann (Kangaroo Island Veterinary Hospital) for assistance with sample collection and feedback on the study design. We thank Johann Schroder for helpful feedback on the study design and manuscript. 


\section{References}

1. Kleemann DO, Walker SK: Fertility in South Australian commercial Merino flocks: sources of reproductive wastage. Theriogenology 2005, 63(8):2075-2088.

2. Fowler D: Lamb marking performance for ultrasound scanned ewes in Australian sheep flocks (project AHW.131). Australia MaL; North Sydney: 2007: Available at: Accessed:

3. Clune T, Besier S, Hair S, Hancock S, Lockwood A, Thompson A, Jelocnik M, Jacobson C: Chlamydia pecorum detection in aborted and stillborn lambs from Western Australia. Vet Res 2021, 52(1):84.

4. Dawson AC, Ashander LM, Appukuttan B, Woodman RJ, Dubey JP, Whiley H, Smith JR: Lamb as a potential source of Toxoplasma gondii infection for Australians. Aust N Z J Public Health 2020, 44(1):49-52.

5. Guo M, Dubey JP, Hill D, Buchanan RL, Gamble HR, Jones JL, Pradhan AK: Prevalence and risk factors for Toxoplasma gondii infection in meat animals and meat products destined for human consumption. J Food Prot 2015, 78(2):457-476.

6. Dubey JP, Murata FHA, Cerqueira-Cézar CK, Kwok OCH, Su C: Economic and public health importance of Toxoplasma gondii infections in sheep: 2009-2020. Vet Parasitol 2020, 286(C):109195-109195.

7. Innes EA, Bartley PM, Buxton D, Katzer F: Ovine toxoplasmosis. Parasitology 2009, 136(14):18871894.

8. Costa FTR, Nogueira DB, Oliveira MAG, Silva SS, Silva RF, Sarmento WF, Azevedo SS, Gennari SM, Pena HFJ, Brasil AWL et al: Vertical transmission of Toxoplasma gondii in naturally infected ewes in the semiarid region of Brazil. Comp Immunol Microbiol Infect Dis 2021, 74:101595-101595.

9. Williams RH, Morley EK, Hughes JM, Duncanson P, Terry RS, Smith JE, Hide G: High levels of congenital transmission of Toxoplasma gondii in longitudinal and cross-sectional studies on sheep farms provides evidence of vertical transmission in ovine hosts. Parasitology 2005, 130(3):301-307.

10. Buxton D, Innes EA: A commercial vaccine for ovine toxoplasmosis. Parasitology 1995, 110(S1):S11S16.

11. Dubey JP, Kirkbride CA: Enzootic toxoplasmosis in sheep in North-Central United States. The Journal of Parasitology 1989, 75(5):673-676.

12. Katzer F, Brülisauer F, Collantes-Fernández E, Bartley PM, Burrells A, Gunn G, Maley SW, Cousens C, Innes EA: Increased Toxoplasma gondii positivity relative to age in 125 Scottish sheep flocks; evidence of frequent acquired infection. Vet Res 2011, 42(1):121-121.

13. Clune T, Beetson S, Besier S, Knowles G, Paskin R, Rawlin G, Suter R, Jacobson C: Ovine abortion and stillbirth investigations in Australia. Aust Vet J 2021, 99(3):72-78.

14. Munday BL: Prevalence of toxoplasmosis in Tasmanian meat animals. Aust Vet J 1975, 51(6):315316.

15. Plant JW, Freeman P, Saunders E: Serological survey of the prevalence of Toxoplasma gondii antibodies in rams in sheep flocks in New South Wales. Aust Vet J 1982, 59(3):87-89. 
16. O'Donoghue PJ, Riley MJ, Clarke JF: Serological survey for Toxoplasma infections in sheep. Aust Vet J 1987, 64(2):40-45.

17. Kiermeier A, Hamilton D, Smith G: National serological baseline survey of <bi>Toxoplasma gondii $\mathrm{i}</$ bi $>\mathrm{n}$ lambs and sheep (project code A.MFS.0129). Australia MaL; North Sydney, Australia: 2008: Available at: Accessed:

18. McGregor H, Harvey R: A pilot survey of the prevalence of serum antibodies against $<\mathrm{bi}>$ Toxoplasma gondii $</ \mathrm{bi}>$ and risk factors for transmission of $<\mathrm{bi}>\mathrm{T}$. gondii</bi $>$ to sheep in the Tumbarumba shire of New South Wales Flock \& Herd; 2011. Available at:

[http://www.flockandherd.net.au/sheep/reader/toxoplasmosis.html] Accessed: May 2018

19. Taggart $P$, McAllister M, Rutley D, Caraguel C: Oesophageal sarcocystosis observed at slaughter provides a reliable and efficient proximate measure of Toxoplasma gondii seroprevalence in sheep. Aust Vet J 2020, 98(7):305-311.

20. Lanyon SR, O'Handley RM: Relationship between Toxoplasma gondii seroprevalence and lamb marking in South Australian sheep flocks. Aust Vet J 2020, 98(11):525-528.

21. Hamilton D, Hodgson K, Howard A, Jolley J, Mahbub K, Torok V, McAllister M: Investigation of the viability and national serological prevalence of $<$ bi $>$ Toxoplasma gondii $</$ bi $>$ in Australian sheep (Final Report V.MFS.0419). Meat and Livestock Australia; North Sydney, Australia: 2021: Available at: https://www.mla.com.au/research-and-development/reports/2019/toxoplasma-gondii-sheep/\# Accessed: September 2021

22. Savio E, Nieto A: Ovine toxoplasmosis: Seroconversion during pregnancy and lamb birth rate in Uruguayan sheep flocks. Vet Parasitol 1995, 60(3):241-247.

23. Kenyon PR, Pinchbeck GL, Perkins NR, Morris ST, West DM: Identifying factors which maximise the lambing performance of hoggets: a cross sectional study. NZ Vet J 2004, 52(6):371-377.

24. Clune T, Lockwood A, Hancock S, Bruce M, Thompson AN, Beetson S, Campbell AJ, Glanville E, Brookes $\mathrm{D}$, Trengove $\mathrm{C}$ et al: $<\mathrm{bi}>\mathrm{Neospora}$ caninum $</ \mathrm{bi}>$ is not an important contributor to poor reproductive performance of primiparous ewes from southern Australia: evidence from a crosssectional study. Parasitol Res 2021, Available online.

25. Kenyon PR, Thompson AN, Morris ST: Breeding ewe lambs successfully to improve lifetime performance. Small Rumin Res 2014, 118(1-3):2-15.

26. Castaño P, Fuertes $M$, Regidor-Cerrillo J, Ferre I, Fernández M, Ferreras MC, Moreno-Gonzalo J, González-Lanza C, Pereira-Bueno J, Katzer F et al: Experimental ovine toxoplasmosis: influence of the gestational stage on the clinical course, lesion development and parasite distribution. Vet Res 2016, 47(1):43.

27. Esteban-Redondo I, Innes EA: Detection of Toxoplasma gondii in tissues of sheep orally challenged with different doses of oocysts. Int J Parasitol 1998, 28(9):1459.

28. Castaño P, Fuertes M, Ferre I, Fernández M, Ferreras MdC, Moreno-Gonzalo J, González-Lanza C, Katzer F, Regidor-Cerrillo J, Ortega-Mora LM et al: Placental thrombosis in acute phase abortions during experimental Toxoplasma gondii infection in sheep. Vet Res 2014, 45(1):9-9. 
29. Buxton D, Brebner J, Wright S, Maley SW, Thomson KM, Millard K: Decoquinate and the control of experimental ovine toxoplasmosis. Vet Rec 1996, 138(18):434-436.

30. Owen MR, Clarkson MJ, Trees AJ: Acute phase toxoplasma abortions in sheep. Vet Rec 1998, 142(18):480-482.

31. Owen MR, Clarkson MJ, Trees AJ: Diagnosis of toxoplasma abortion in ewes by polymerase chain reaction. Vet $\operatorname{Rec} 1998,142(17): 445-448$.

32. Munday BL, Dubey JP: Serology of experimental toxoplasmosis in pregnant ewes and their foetuses. Aust Vet J 1986, 63(11):353-355.

33. Sager H, Gloor M, Tenter A, Maley S, Hässig M, Gottstein B: Immunodiagnosis of primary Toxoplasma gondii infection in sheep by the use of a P30 IgG avidity ELISA. Parasitol Res 2003, 91(2):171-174.

34. Dubey JP, Beattie CP: Toxoplasmosis of Animals and Man. Boca Raton, Florida: CRC Press; 1988.

35. Ostfeld N, Islam MM, Jelocnik M, Hilbe M, Sydler T, Hartnack S, Jacobson C, Clune T, Marsh I, Sales N et al: Chlamydia pecorum-induced arthritis in experimentally-induced and naturally infected sheep. Vet Pathol 2020.

36. Masala G, Porcu R, Madau L, Tanda A, Ibba B, Satta G, Tola S: Survey of ovine and caprine toxoplasmosis by IFAT and PCR assays in Sardinia, Italy. Vet Parasitol 2003, 117(1):15-21.

37. Pereira-Bueno J, Quintanilla-Gozalo A, Pérez-Pérez V, Álvarez-García G, Collantes-Fernández E, OrtegaMora LM: Evaluation of ovine abortion associated with Toxoplasma gondii in Spain by different diagnostic techniques. Vet Parasito/ 2004, 121(1):33-43.

38. Dubey JP: Toxoplasmosis in sheep-The last 20 years. Vet Parasito/2009, 163(1):1-14.

39. IDvet: Internal validation report: ID Screen ${ }^{\circledR}$ Toxoplasmosis Indirect Multi-species. In. France: IDvet, Innovative Diagnostics; 2018.

40. Dempster RP, Wilkins M, Green RS, de Lisle GW: Serological survey of Toxoplasma gondii and Campylobacter fetus fetus in sheep from New Zealand. N Z Vet J 2011, 59(4):155.

41. Shapiro K, Bahia-Oliveira L, Dixon B, Dumètre A, de Wit LA, VanWormer E, Villena I: Environmental transmission of Toxoplasma gondir: Oocysts in water, soil and food. Food Waterborne Parasitol 2019, 15:e00049.

42. Stelzer S, Basso W, Benavides Silván J, Ortega-Mora LM, Maksimov P, Gethmann J, Conraths FJ, Schares G: Toxoplasma gondii infection and toxoplasmosis in farm animals: Risk factors and economic impact. Food and Waterborne Parasitology 2019, 15:e00037.

43. Subedi S, Sharma B, Singh S, Bindari YR: Sero-prevalence of Toxoplasma gondii in sheep in different geographical regions of Nepal. Veterinary and Animal Science 2018, 5:7-9.

44. Abd El-Razik KA, Barakat AMA, Hussein HA, Younes AM, Elfadaly HA, Eldebaky HA, Soliman YA: Seroprevalence, isolation, molecular detection and genetic diversity of Toxoplasma gondii from small ruminants in Egypt. $J$ Parasit Dis 2018, 42(4):527-536. 
45. Rasti S, Marandi N, Abdoli A, Delavari M, Mousavi SGA: Serological and molecular detection of Toxoplasma gondii in sheep and goats in Kashan, Central Iran. J Food Saf 2018, 38(2):e12425.

46. Australian Government Bureau of Meteorology: Australian Climate Averages - Rainfall 2021. Available at: [http://www.bom.gov.au/jsp/ncc/climate_averages/rainfall/index.jsp] Accessed: June 2021

47. Mainar-Jaime RC, Barberán M: Evaluation of the diagnostic accuracy of the modified agglutination test (MAT) and an indirect ELISA for the detection of serum antibodies against Toxoplasma gondii in sheep through Bayesian approaches. Vet Parasito/ 2007, 148(2):122-129.

48. Brown LD, Cat TT, DasGupta A: Interval estimation for a proportion. Stat Sci 2001, 16(101-133).

49. Sergeant ESG: Epitools epidemiological calculators Ausvet Pty Ltd.; 2021. Available at: [http://epitools.ausvet.com.au] Accessed: 20 February 2021

50. Speybroeck N, Devleesschauwer B, Joseph L, Berkvens D: Misclassification errors in prevalence estimation: Bayesian handling with care. Int J Public Health 2013, 58(5):791-795.

\section{Figures}

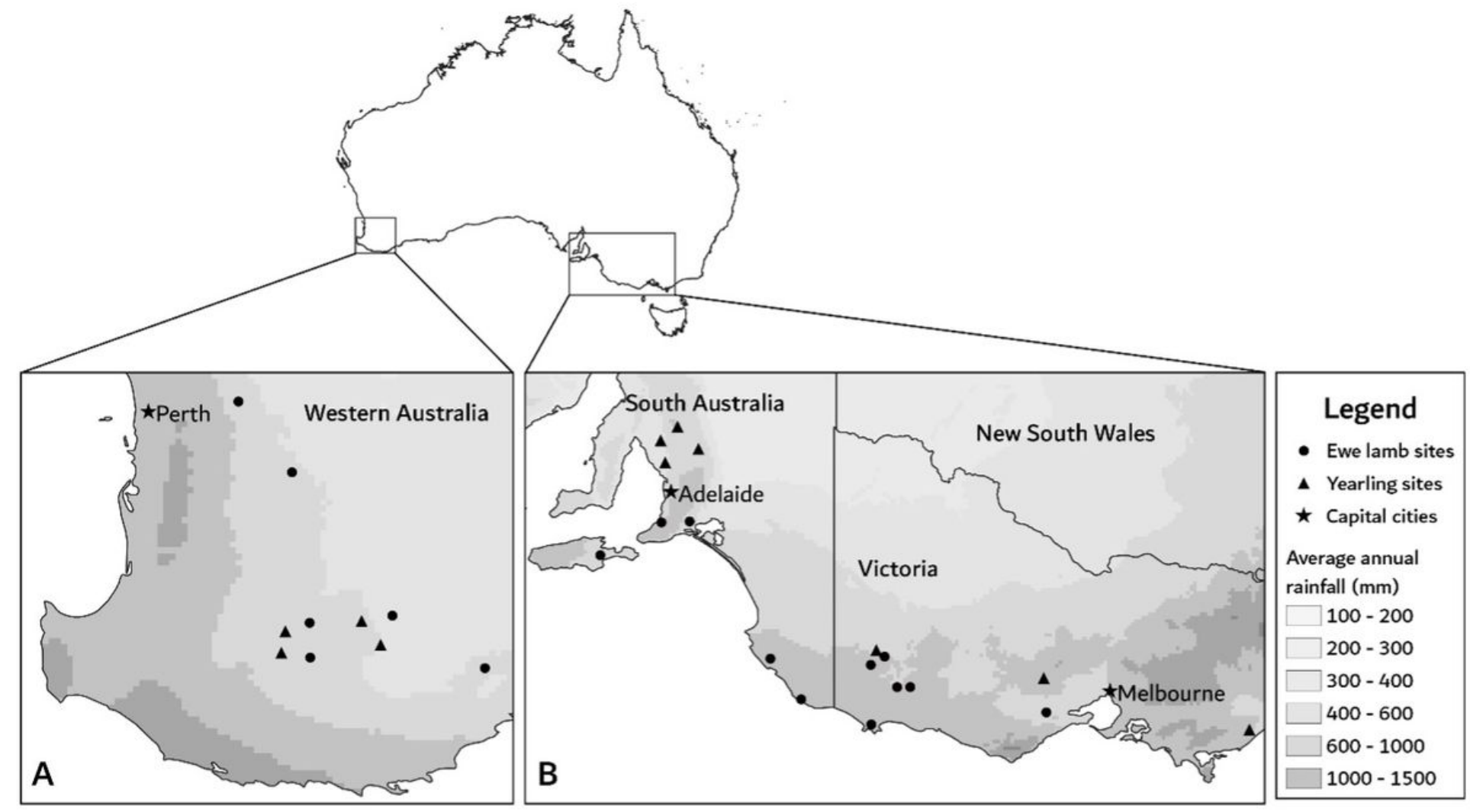

Figure 1

Approximate location of farms sampled in Western Australia (A) and South Australia and Victoria (B) adapted from Clune et al. [24]. Average annual rainfall data was sourced from Australian Government 
Bureau of Meteorology [46]

\section{Supplementary Files}

This is a list of supplementary files associated with this preprint. Click to download.

- AdditionalFile1.pdf

- AdditionalFile2.pdf

- AdditionalFile3.pdf

- AdditionalFile4.pdf

- AdditionalFile5.pdf 